\title{
Visiting old, innovating new ${ }^{\dagger}$
}

by

\author{
Shoichi KIKUCHI*
}

\begin{abstract}
Key words: Nitriding, Fine particle peening, Fatigue, Corrosion, Hardness, Residual stress, Austenitic stainless steel
\end{abstract}
\section{Editorial}

Biomaterials are required to possess various properties, such as high strength, corrosion resistance and tribological resistance. A hybrid surface modification, which combines fine particle peening (FPP) with gas nitriding at low temperature, improved both the fatigue properties and electrochemical characteristics of austenitic stainless steels due to the formation of a nitrided layer containing expanded austenite, called the "S-phase". Therefore, this original paper $^{1)}$ was recommended by the JSMS Committee on Biomedical Materials and selected for the special issue "Visiting old, innovating new", because the hybrid surface treatment proposed in this paper would be an effective method for biomaterials utilized under severe conditions. The original Japanese paper ${ }^{1)}$ was translated into a review paper in English with slight modification and addition of a few recent references.

\section{Introduction}

Austenitic stainless steels exhibit lower fatigue strength and tribological resistance than carbon steels; therefore, nitriding is usually performed for austenitic stainless steels utilized as mechanical components. Gas nitriding has been widely used in various fields of engineering due to its high productivity, while a passive film at the surface of austenitic stainless steels, which prevents nitrogen diffusion, should be removed when gas nitriding is performed. Generally, acid cleaning and gas reduction processes are performed prior to gas nitriding for removal of the passive film; however, these chemical processes cause some problems, namely, damage to the furnace, and adverse environmental effects due to the need for disposal of waste acid ${ }^{2}$.

Therefore, an efficient pre-treatment process was introduced prior to gas nitriding. For example, Hamaishi et al. ${ }^{3)-5)}$ reported that nitrogen diffusion into austenitic stainless steels was facilitated during gas nitriding due to the formation of iron oxides induced by atmospheric preheating. The present authors ${ }^{6}$ ) have reported the introduction of fine particle peening (FPP) as a pre-processing step to facilitate the diffusion of nitrogen into the material ${ }^{7)-11)}$, which results in the formation of a nitrided layer on austenitic stainless steels.

However, nitriding, which is generally performed at 500-570 ${ }^{\circ} \mathrm{C}$, was found to reduce the corrosion resistance of these steels, because the concentration of chromium in the substrate is reduced due to the formation of chromium nitrides during nitriding ${ }^{12)}$. Ichii et al. ${ }^{13)}$ developed low temperature nitriding at $400{ }^{\circ} \mathrm{C}$ to suppress the reduction of corrosion resistance and formed an expanded form of austenite, called the S-phase, with high corrosion resistance ${ }^{14)}$. Furthermore, compressive residual stress was generated ${ }^{15}$ ) due to the formation of the S-phase; therefore, low temperature nitriding could improve the fatigue properties of austenitic stainless steels ${ }^{16}$. However, the long nitriding duration required due to the reduction in the nitrogen diffusion rate caused by the low nitriding temperature is problematic.

In this study, in order to form a nitrided core and facilitate nitrogen diffusion into austenitic stainless steels, we performed FPP treatment prior to gas nitriding. The aims of this study are to characterize the nitrided layer generated by gas nitriding at various temperatures after FPP treatment, and to examine the effect of the FPP treatment on the fatigue properties and electrochemical characteristics of surface-modified austenitic stainless steel (JIS-SUS316).

\section{Experimental Procedures}

\subsection{Materials and Specimen}

The material used in this study was JIS-SUS316 austenitic stainless steel with the chemical composition shown in Table 1. Cylindrical specimens $(\varnothing 15 \mathrm{~mm}$ with a thickness of $4 \mathrm{~mm}$ ) were prepared for the purpose of characterizing the microstructure and examining the electrochemical characteristics of the surface-modified steels. SUS316 steel bars of $16 \mathrm{~mm}$ diameter were also machined into the shape and dimensions shown in Fig. 1. The stress concentration factor of the specimen for the rotating bending fatigue test was 3.35. In this study, notched specimens were used to prevent subsurface-induced fatigue failure ${ }^{6}$. After machining, the cylindrical specimens were polished with

$\dagger \quad$ Received Aug.6, 2020 (C2021 The Society of Materials Science, Japan

This paper was originally published in Japanese in J. Soc. Mater. Sci., Jpn. Vol.61, No.8, pp.680-685, (2012).

* Member: Dept. of Mech. Eng., Shizuoka Univ., Naka-ku, Hamamatsu 432-8561, Japan 
emery paper (\#320 to \#1200), and then mirror-finished using a $\mathrm{SiO}_{2}$ suspension ( $\mathrm{P}$ series). Fatigue test specimens were electrochemically polished to remove the machined layer ( $\mathrm{P}$ series).

The FPP treatment was performed under the conditions: peening pressure $0.1,0.4$ and $0.6 \mathrm{MPa}$, nozzle distance 100 $\mathrm{mm}$, particle supply rate $2 \mathrm{~g} / \mathrm{s}$ and peening time 10 and $30 \mathrm{~s}$. The shot particles used in this study were $63 \mu \mathrm{m}$ in diameter and made from a high-speed tool steel with the chemical composition shown in Table 2.

The gas nitriding process was then performed at 400, 475 and $550^{\circ} \mathrm{C}$ for $20,3.5$ and 2 hours, respectively, in a nitrogen and ammonia environment to form a nitrided layer $20 \mu \mathrm{m}$ in thickness. Figure 2 shows a flowchart illustrating the specimen preparation; four types of specimens were prepared with different surface-modified layers. In the series name, "F" represents FPP, "N" represents nitriding and the number represents the nitriding temperature.

\section{$3 \cdot 2$ Testing}

The depth distribution of the micro-Vickers hardness was measured for the cylindrical specimens. The surface microstructures of the surface-modified specimens were characterized using optical microscopy, scanning electron microscopy (SEM), glow discharge optical emission spectroscopy (GD-OES) and X-ray photoelectron spectroscopy (XPS). The crystal structures of the cylindrical specimens were identified using X-ray diffraction (XRD) with $\mathrm{Cu} \mathrm{K} \alpha$ radiation.

Electrochemical polarization tests were performed using a three-electrode electrochemical cell connected to a computer-driven potentiostat. The test specimen was the working electrode, platinum was used as the counter

Table 1 Chemical composition of SUS316 steel. (mass\%)

\begin{tabular}{cccccccccccc}
\hline $\mathrm{C}$ & $\mathrm{Si}$ & $\mathrm{Mn}$ & $\mathrm{P}$ & $\mathrm{S}$ & $\mathrm{Ni}$ & $\mathrm{Cr}$ & $\mathrm{Mo}$ & $\mathrm{V}$ & $\mathrm{Cu}$ & $\mathrm{Ti}$ & $\mathrm{Al}$ \\
\hline \hline 0.04 & 0.33 & 1.31 & 0.039 & 0.019 & 11.06 & 16.01 & 2.09 & 0.05 & 0.45 & 0.002 & 0.073
\end{tabular}

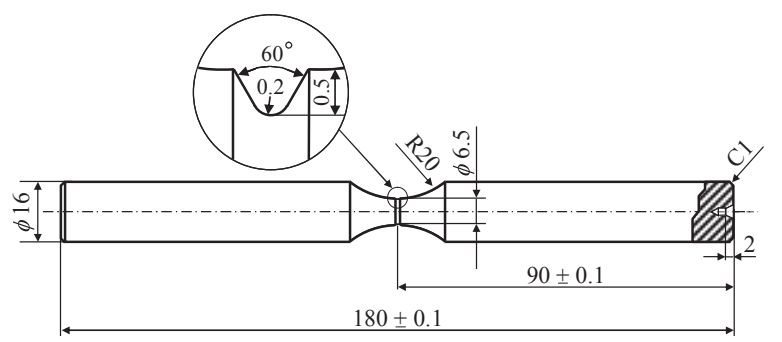

Fig. 1 Specimen configuration $\left(K_{\mathrm{t}}=3.35\right)$.

Table 2 Chemical composition of SKH59 steel. (mass\%)

\begin{tabular}{cccccccccc}
\hline $\mathrm{C}$ & $\mathrm{Si}$ & $\mathrm{Mn}$ & $\mathrm{P}$ & $\mathrm{S}$ & $\mathrm{Cr}$ & $\mathrm{Mo}$ & $\mathrm{V}$ & $\mathrm{W}$ & $\mathrm{Co}$ \\
\hline \hline 2.2 & $<0.5$ & $<0.5$ & $<0.05$ & $<0.05$ & 4 & 7.5 & 5.5 & 8 & 10 \\
\hline
\end{tabular}

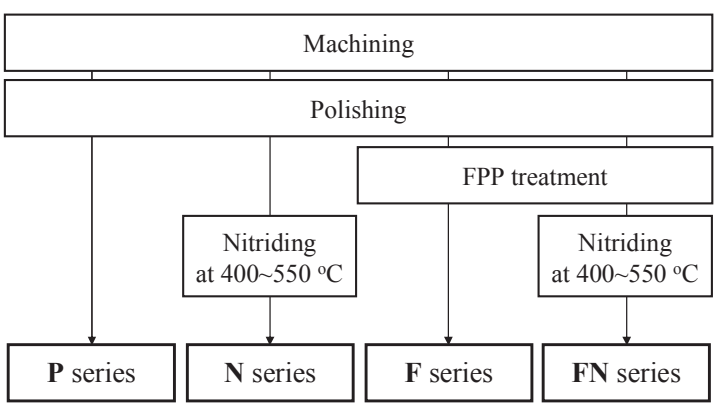

Fig. 2 Flowchart illustrating the specimen preparation processes.

electrode, and the saturated calomel electrode (SCE) was used as the reference electrode. As the electrolyte solution, 3 $\mathrm{wt} \% \mathrm{NaCl}$ solution was deaerated with nitrogen gas for 20 min prior to use to decrease the oxygen concentration and maintained at $25{ }^{\circ} \mathrm{C}$. In the anodic potentiodynamic polarization test, the potential was increased at a sweep rate of $40 \mathrm{mV} / \mathrm{min}$ after holding at the self-potential for $30 \mathrm{~s}$.

Residual stress was also measured at the transverse section of the smallest diameter of the fatigue test specimen using XRD using $\mathrm{Cr} \mathrm{K} \alpha$ radiation. A Position-Sensitive Proportional Counter (PSPC) system based on the $\sin ^{2} \psi$ method was used under the conditions: collimator diameter 2 $\mathrm{mm}$, measuring time $60 \mathrm{~s}$ and measurement error less than $100 \mathrm{MPa}$. Since residual stress measurement was difficult for the notched specimens, we measured the residual stress of a smooth specimen with the same surface modification.

High-cycle fatigue tests were performed at room temperature in air using an Ono-type rotating bending fatigue testing machine at $1200 \mathrm{rpm}$ to suppress the rise of temperature. In this study, the fatigue limit was defined as the maximum stress amplitude applied to the specimen without fatigue failure. In order to investigate the fracture mechanism, fracture surfaces were observed with an SEM.

\section{Results and Discussion}

\section{4-1 Effect of Nitriding Temperature in Hybrid Surface} Treatment on Nitrided Layer Formed on SUS316

First, the AISI 316 austenitic stainless steels treated with the hybrid surface modification were characterized. Figure 3 shows the typical features of the microstructures observed by an optical microscope for the FN series after etching with a $10 \%$ oxalic acid solution. In Fig. 3(a), a local stratification pattern was observed near the surface of an $F$ series specimen. This stratification pattern is generated by the concentration of severe plastic deformation ${ }^{17)-20)}$. It was reported that the stratification-patterned layer contained a fine-grained structure $^{21)-23)}$. Figs. 3(b)-(d) reveal the presence of a unique black structure near the surface of the FN series.

Figure 4 shows the micro-Vickers hardness distribution of the cylindrical specimens at various cross-sectional depths. In 
this figure, the dotted line represents the average hardness value of the $\mathrm{P}$ series. In the case of the nitriding-only specimens (N400, N475 and N550 series), the hardness values were almost the same as that of the $\mathrm{P}$ specimen, although nitriding was performed. This result indicates that nitrogen diffusion was suppressed during the gas nitriding due to the passive film on austenitic stainless steel. On the other hand, in the case of the FN series specimens (FN400, FN475 and FN550 series), which were treated with both FPP and gas nitriding, the hardness values near the surface were much higher than those of the $\mathrm{F}$ series specimens. These results mean that FPP introduced as a pre-processing step facilitated the diffusion of nitrogen into the austenitic stainless steels during the subsequent gas nitriding. Figure 4 also reveals that the thickness of the hardened layer was approximately $20 \mu \mathrm{m}$; therefore, the unique black structure of

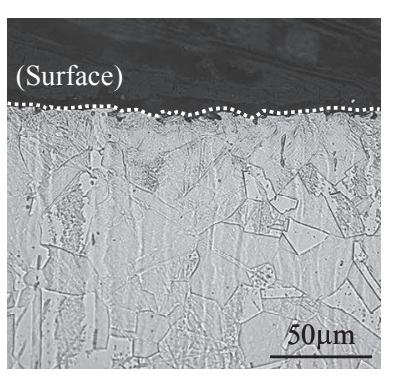

(a) F series

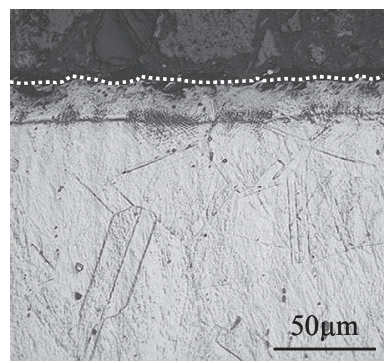

(c) FN475 series

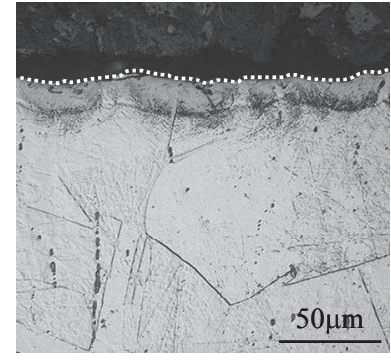

(b) FN400 series

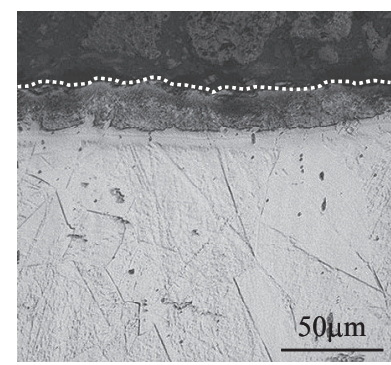

(d) FN550 series
Fig. 3 Longitudinal optical micrographs of the F and FN series etched with $10 \%$ oxalic acid solution.

(Peening pressure: $0.6 \mathrm{MPa}$, Peening time: $10 \mathrm{~s}$ )

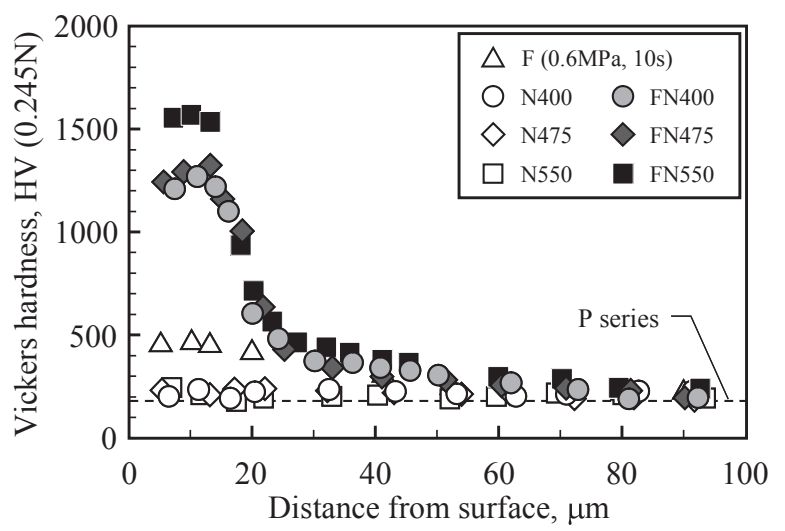

Fig. 4 Depth distribution of Vickers hardness. (Peening pressure: 0.6 MPa, Peening time: $10 \mathrm{~s}$ )
$20 \mu \mathrm{m}$ thickness observed in Figs. 3(b)-(d) corresponded to the nitrided layer. Furthermore, the hardness values of the FN series tended to increase with the nitriding temperature.

To clarify the reason for the variation in surface hardness depending on the nitriding temperature, crystal structures of the FN series were analyzed using XRD. The XRD analysis (Fig. 5) revealed the diffraction peaks of $\mathrm{Fe}_{4} \mathrm{~N}$ in the $\mathrm{FN} 475$ and FN550 series. In contrast, the peaks of $\mathrm{Fe}_{4} \mathrm{~N}$ were not detected in the FN400 series, but the peaks of the S-phase were observed.

Characterization of the nitrided layer induced by the hybrid surface modification depended on the gas nitriding temperature, with the S-phase being formed with low temperature nitriding.

\subsection{Effect of Hybrid Surface Treatment on Corrosion Characteristics of SUS316}

Figure 6 shows the anodic polarization curves for the FN400, FN475, FN550 and P series. A rapid increase in current density was observed in the FN550 series at $-0.1 \mathrm{~V}$, which was higher than that of the P series. This is because the Cr concentration was reduced in the FN550 series due to the formation of chromium nitrides $\left(\mathrm{CrN}\right.$ and $\left.\mathrm{Cr}_{2} \mathrm{~N}\right)$ observed in the XPS spectrum ${ }^{24)}$. In contrast, no rapid increase in current

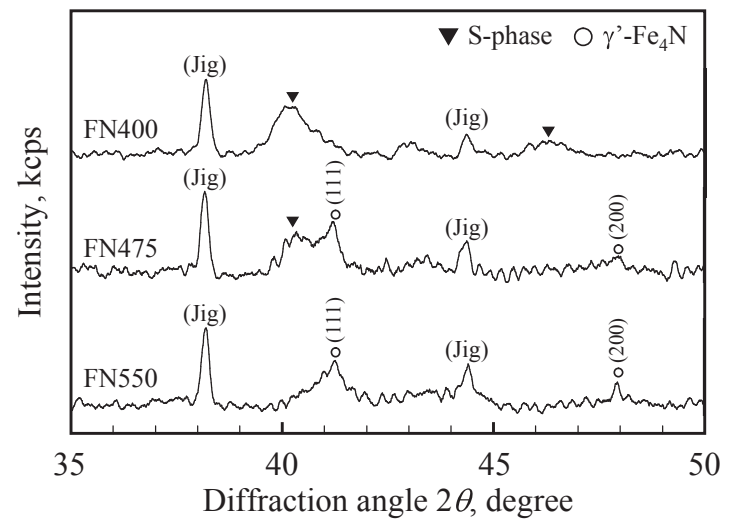

Fig. $5 \mathrm{X}$-ray diffraction patterns ( $\mathrm{Cu}$ radiation). (Peening pressure: $0.6 \mathrm{MPa}$, Peening time: $10 \mathrm{~s}$ )

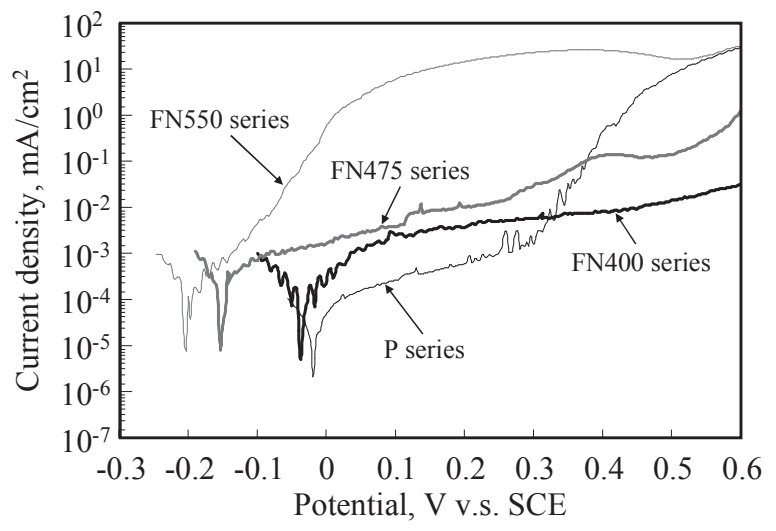

Fig. 6 Anodic polarization curves.

(Peening pressure: 0.6 MPa, Peening time: $10 \mathrm{~s}$ ) 
density was observed in the FN400 and FN475 series at approximately $0.3 \mathrm{~V}$, which corresponded to the pitting potential of the $\mathrm{P}$ series. This is because the S-phase was formed on the surfaces of the FN400 and FN475 series samples, as shown in Fig. 5.

Thus, the electrochemical characteristics of austenitic stainless steels were dependent on the nitriding temperature, and low temperature nitriding improved the electrochemical characteristics.

\subsection{Mechanism of Nitrided Layer Formation by Hybrid Surface Treatment}

In general, a passive film prevents nitrogen from diffusing into austenitic stainless steel. FPP could form fine-grained structures, which increased the nitrogen diffusion rate, but did not change the chemical composition of the passive film on the materials. In this section, the mechanism of the generation of a nitrided layer on austenitic stainless steel pre-treated with FPP was elucidated based on the microstructural changes induced by FPP.

The passive film on the FPP-treated specimen was evaluated by electrochemical corrosion tests. Figure 7 shows the anodic polarization curves for the $\mathrm{F}$ and $\mathrm{P}$ series. In both series, a passivation region was observed because of the passive film formed on the austenitic stainless steel. However, the current density in the $\mathrm{F}$ series was dependent on the pressure of the FPP, and an unstable passive region was observed in the FPP-treated specimens. This could possibly be attributed to a transferred layer ${ }^{17), 25)-33)}$ of steel shot particles.

To test this hypothesis, depth profiles of tungsten, which is a component of the steel shot particles used in this study, were measured using GD-OES. Figure 8 presents the depth profiles of tungsten in the $\mathrm{F}$ and $\mathrm{P}$ series, respectively. The signal intensity on the vertical axis is proportional to the elemental concentration and the sputtering time on the horizontal axis corresponds to the depth from the surface. The signal intensity of the $\mathrm{P}$ series remained constant, whereas a $\mathrm{W}$-rich region was observed in the $\mathrm{F}$ series, and the signal

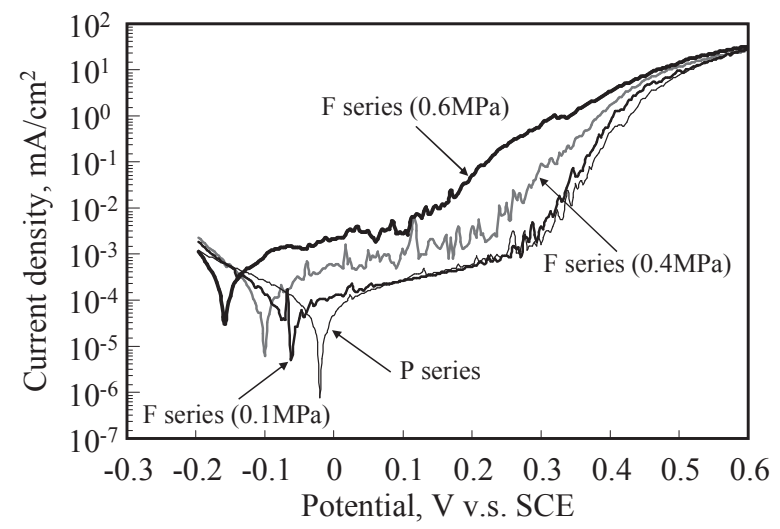

Fig. 7 Anodic polarization curves. (Peening time: $10 \mathrm{~s}$ )

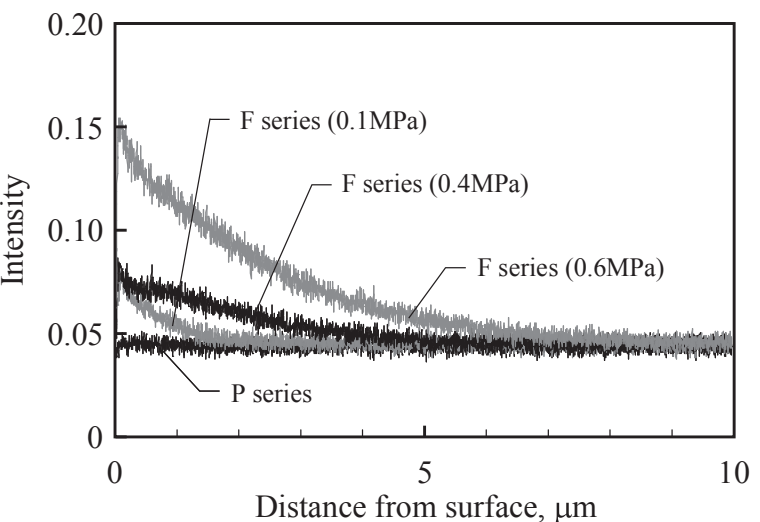

Fig. 8 Tungsten distribution with depth. (Peening time: 10s)

intensity tended to increase with the peening pressure. This result means that a transferred layer from the steel shot particles was formed on the F series, which influenced the electrochemical properties of the austenitic stainless steel as shown in Fig. 7.

Based on these results, nitrided cores may be formed in the transferred shot particle layer during the subsequent nitriding process. To verify this assumption, an $\mathrm{F}$ series specimen was polished to remove transferred shot particles and subsequently treated by gas nitriding. As a result, a nitrided layer was not observed on this F series specimen ${ }^{24)}$, which suggests that the existence of a transferred shot particle layer is important for the generation of a nitrided layer on the surface of austenitic stainless steel.

The nitrogen diffusion mechanism is illustrated schematically in Fig. 9. Figure 9(a) represents the formation of the transferred shot particle layer and fine-grained structure by FPP, and Figures 9(b)-(d) represent the formation of nitrided cores and nitrogen diffusion during the subsequent gas nitriding. Shot particles transferred onto the FPP-treated surface were nitrided (Fig. 9(b)), forming the nitrided cores. Then, nitrogen diffusion occurred in the nitrided shot particles, and nitrogen diffused rapidly throughout the

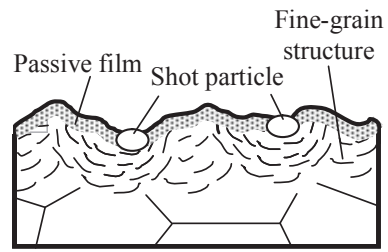

(a)

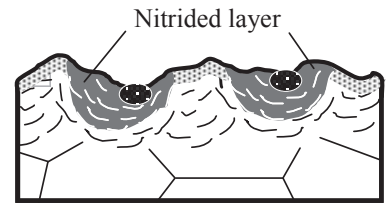

(c)

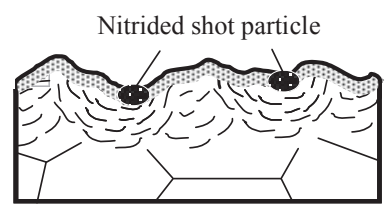

(b)

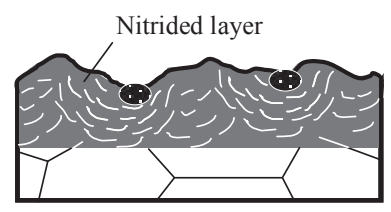

(d)
Fig. 9 Schematic illustration of the mechanism proposed for the formation of a nitrided layer. 
fine-grained structure ${ }^{6), 7), 22)}$ (Fig. 9(c)), resulting in the formation of a nitrided layer (Fig. 9(d)). The crystal structure of the nitrided layer depended on the nitriding temperature, with the S-phase being formed by low-temperature nitriding.

\subsection{Effect of Hybrid Surface Treatment on Fatigue Properties of SUS316}

Figure 10 shows the results of high-cycle fatigue tests. In this figure, the vertical axis represents the nominal stress amplitude applied to the specimen surface. The fatigue limits of the $\mathrm{N}$ series were similar to those of the $\mathrm{F}$ and $\mathrm{P}$ series. On the other hand, the fatigue limits of the FN series were higher than those of the F and $\mathrm{P}$ series. The results show that the fatigue limits of the FN series did not depend on the nitriding temperature. As shown by SEM observation of the fracture surfaces (Fig. 11), the F and FN series failed in the surface fracture mode. Therefore, the improvement in the fatigue properties achieved by the hybrid surface modification is attributed to the formation of the nitrided layer.

Figure 12 shows the compressive residual stress measured at the surface under two conditions: $2 \theta=148.5^{\circ}$ and $156.4^{\circ}$ at the $\alpha-\mathrm{Fe}$ (211) plane. High compressive residual stress was generated in the $\mathrm{F}$ series. The FN series exhibited almost the same compressive residual stress values as the $\mathrm{F}$ series. This result suggests that the differences between the $\mathrm{F}$ and $\mathrm{FN}$ series in terms of the fatigue limit can be attributed to the differences in surface hardness.

In order to clarify the mechanism by which compressive residual stress is generated by the hybrid surface modification, FPP-treated specimens (F series) were heated under the same conditions as in the nitriding process, but in a vacuum environment (FH series). The value of compressive residual stress measured in the F-H series was lower than that of the F series. This result means that compressive residual stress generated by FPP was released due to the high temperature ${ }^{6), 7)}$ Furthermore, the FN series showed higher compressive residual stress compared with the FH series; therefore, compressive residual stress was released and generated during the subsequent gas nitriding step, simultaneously.

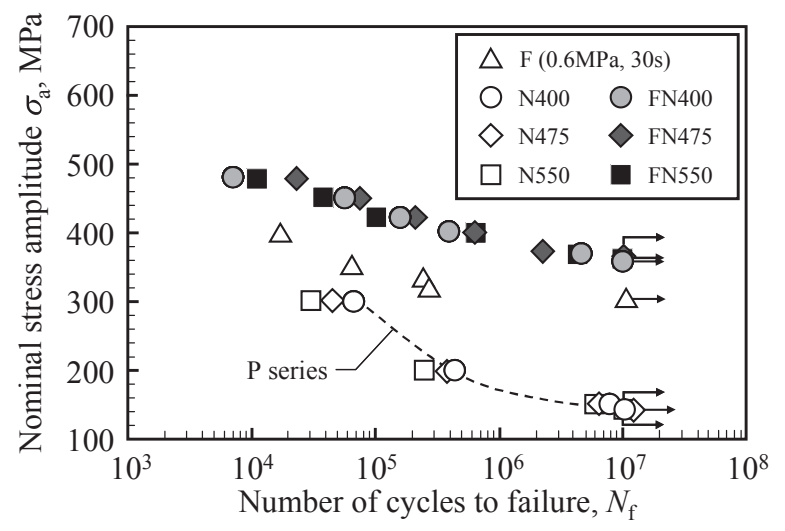

Fig. 10 Results of fatigue tests. $\left(K_{\mathrm{t}}=3.35\right)$

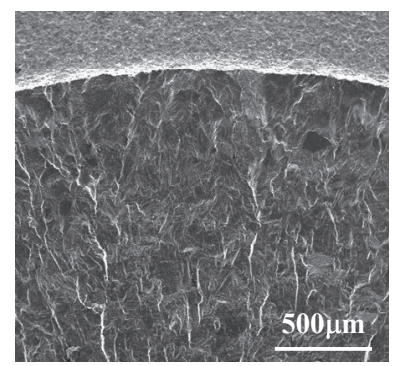

(a) F $\left(N_{\mathrm{f}}=16,900\right)$

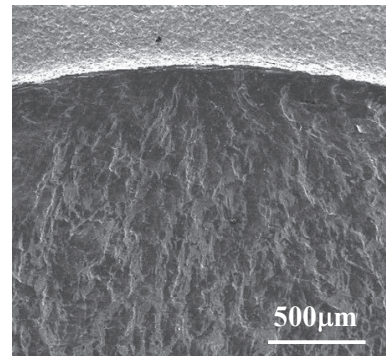

(c) FN475 $\left(N_{\mathrm{f}}=633,800\right)$

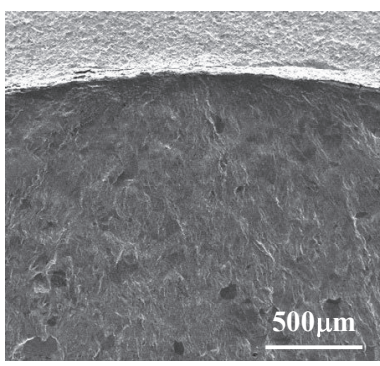

(b) FN400 $\left(N_{\mathrm{f}}=398,600\right)$

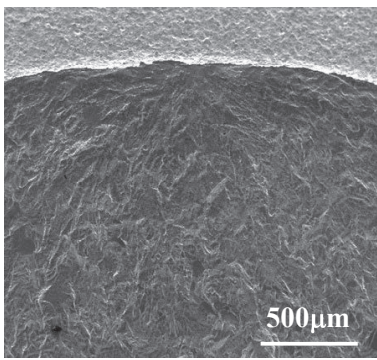

(d) FN550 $\left(N_{\mathrm{f}}=659,300\right)$
Fig. 11 Typical features of fracture surfaces $\left(\sigma_{\mathrm{a}}=400 \mathrm{MPa}\right)$.

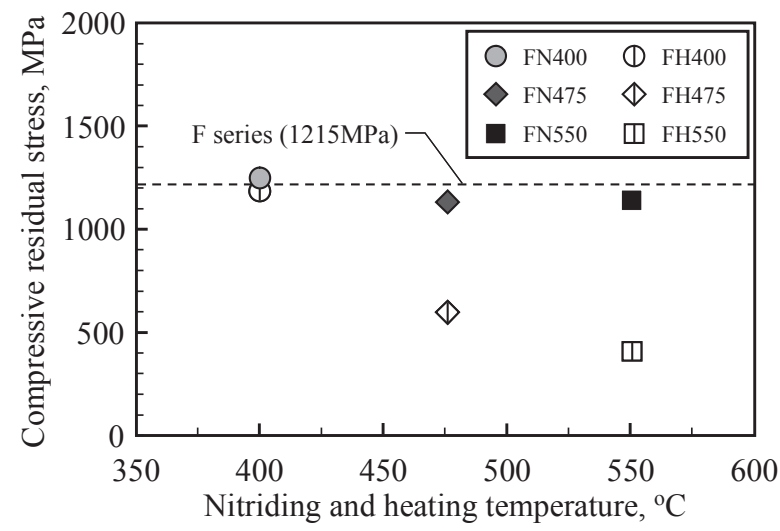

Fig. 12 Results of measuring compressive residual stress at the surface.

Thus, it was demonstrated that FPP treatment prior to gas nitriding is highly effective in improving the electrochemical characteristics and fatigue properties of austenitic stainless steel. This is because a nitrided layer with high hardness and compressive residual stress is formed by the hybrid surface modification.

\section{Conclusion}

In order to facilitate the diffusion of nitrogen into austenitic stainless steel (JIS-SUS316), fine particle peening (FPP) was performed prior to gas nitriding. The effects of the FPP treatment on the gas nitriding behavior and consequent electrochemical and fatigue properties of the austenitic stainless steel were evaluated. Rotating bending fatigue tests were conducted at room temperature on surface-modified austenitic stainless steel. Fatigue fracture mechanisms were also elucidated on the basis of the results of fracture surface observation and microstructural characterization. The 
following conclusions were reached:

1. FPP treatment prior to nitriding enables the generation of a nitrided layer with high hardness on austenitic stainless steel. Expanded austenite, called the S-phase, is formed on surfaces treated by low-temperature nitriding.

2. Hybrid surface modification at low temperature improves the electrochemical characteristics of austenitic stainless steel due to the formation of the S-phase.

3. Nitrogen diffusion occurs in a transferred shot particle layer and is facilitated by the fine-grained structure induced by the FPP treatment.

4. The hybrid surface modification improves the fatigue properties of austenitic stainless steel, and the fatigue limit does not depend on the nitriding temperature.

The authors would like to thank Dr. Kengo Fukazawa for measuring the residual stress.

\section{References}

1) S. Kikuchi, Y. Nakahara, K. Dobashi and J. Komotori, "Effects of FPP/gas nitriding hybrid surface treatment on fatigue properties of austenitic stainless steel (SUS316)", Journal of the Society of Materials Science, Japan, Vol.61, No.8, pp.680-685 (2012).

2) K. Gemma, H. Kawakami and M. Hagiwara, "Effect of $\mathrm{NH}_{3}-\mathrm{O}_{2}$ gas mixtures on the protective oxide film on high chromium alloy steels", Materialwissenschaft und Werkstofftechnik, Vol.24, No.10, pp.378-383 (2004).

3) K. Hamaishi, H. Sueyoshi, S. Kadomatsu, T. Shiomizu and Y. Ohzono, "Effect of preheating in air on gas nitriding of SUS304", Journal of the Japan Institute of Metals, Vol.60, No.6, pp.616-623 (1996).

4) K. Hamaishi, H. Sueyoshi, T. Shiomizu and Y. Ohzono, "Effect of preheating in air on gas nitriding of austenitic stainless steel", Journal of the Japan Institute of Metals, Vol.61, No.11, pp.1198-1205 (1997).

5) K. Hamaishi, H. Sueyoshi and T. Shiomizu, "Effect of processing condition on gas nitriding of austenitic stainless steel", Journal of the Japan Institute of Metals, Vol.62, No.4, pp.310-316 (1998).

6) S. Kikuchi, Y. Nakahara and J. Komotori, "Fatigue properties of gas nitrided austenitic stainless steel pre-treated with fine particle peening", International Journal of Fatigue, Vol.32, No.2, pp.403-410 (2010).

7) S. Kikuchi and J. Komotori, "Effect of fine particle peening treatment prior to nitriding on fatigue properties of AISI 4135 steel", Journal of Solid Mechanics and Materials Engineering, Vol.2, No.11, pp.1444-1450 (2008).

8) S. J. Ji, L. Wang, J. C. Sun and Z. K. Hei, "The effects of severe surface deformation of plasma nitriding of austenitic stainless steel", Surface and Coatings Technology, Vol.19, No.5, pp.81-84 (2005).

9) Y. Lin, J. Lu, L. Wang, T. Xu and Q. Xue, "Surface nanocrystallization by surface mechanical attrition treatment and its effect on structure and properties of plasma nitrided AISI321 stainless steel", Acta Materialia, Vol.54, No.20, pp.5599-5605 (2006).

10) H. Ferkel, M. Glatzer, Y. Estrin and R. Z, Valiev, "RF plasma nitriding of a severely deformed high alloyed steel”, Scripta Materialia, Vol.46, No.9, pp.623-628 (2002).

11) S. Takesue, S. Kikuchi, H. Akebono, Y. Misaka and J. Komotori, "Effect of pre-treatment with fine particle peening on surface properties and wear resistance of gas blow induction heating nitrided titanium alloy", Surface and Coatings Technology, Vol.359, pp.476-484 (2019).

12) K. Ichii, A. Nishimoto, K. Nakao and K. Akamatsu, "Gas nitriding of austenitic stainless steels and a rapid growth mechanism of nitrided layer in the steels", Journal of the Surface Finishing Society of Japan, Vol.54, No.3, pp.200-203 (2003).

13) K. Ichii, K. Fujimura and T. Takase, "Microstructure, corrosion resistance, and hardness of the surface layer in ion nitrided 18-8 stainless steel", Journal of the Japan Society for Heat Treatment, Vol.25, No.4, pp.191-195 (1985).

14) D. Stroz and M. Psoda, "TEM studies of plasma nitrided austenitic stainless steel", Journal of Microscopy, Vol.237, No.3, pp.227-231 (2010).

15) Y. Sun, X. Y. Li and T. Bell, "X-ray diffraction characterisation of low temperature plasma nitrided austenitic stainless steels", Journal of Materials Science, Vol.34, No.19, pp.4793-4802 (1999).

16) K. Masaki and Y. Ochi, "Effect of low temperature gas nitriding and low temperature gas carburizing on high cycle fatigue property in SUS316L", Journal of the Society of Materials Science, Japan, Vol.57, No.6, pp.563-568 (2008).

17) Y. Kameyama, and J. Komotori, "Effect of micro ploughing during fine particle peening process on the microstructure of metallic materials", Journal of Materials Processing Technology, Vol.209, No.20 pp.6146-6155 (2009).

18) Y. Hirota, S. Kikuchi and J. Komotori, "Microstructural change induced by fine particle peening and its effect on elemental diffusion", Journal of Solid Mechanics and Materials Engineering, Vol.2, No.10, pp.1330-1337 (2008).

19) S. Takagi, M. Kumagai, Y. Ito, S. Konuma and E. Shimodaira, "Surface nanocrystallization of carburized steel JIS-SCr420 by fine particle peening", 
Tetsu-to-Hagane, Vol.92, No.5, pp.318-326 (2006).

20) S. Kikuchi, Y. Yasutake and J. Komotori, "Effect of fine particle peening on oxidation resistance of austenitic stainless steel", Journal of Solid Mechanics and Materials Engineering, Vol.6, No.6, pp.431-439 (2012).

21) S. Kikuchi, Y. Hirota and J. Komotori, "Effects of particle size for peening on microstructural changes in steel", Journal of the Japan Society for Abrasive Technology, Vol.54, No.12, pp.720-724 (2010).

22) S. Kikuchi and J. Komotori, "Evaluation of the gas nitriding of fine grained AISI 4135 steel treated with fine particle peening and its effect on the tribological properties", Materials Transactions, Vol.56, No.4, pp.556-562 (2015).

23) S. Kikuchi, Y. Nakamura, K. Nambu and M. Ando, "Effect of shot peening using ultra-fine particles on fatigue properties of 5056 aluminum alloy under rotating bending", Materials Science and Engineering A, Vol.652, pp.279-286 (2016).

24) S. Kikuchi, "Improvement of fatigue properties and its mechanism on steel modified by hybrid surface treatment using fine particle peening", Ph.D. Dissertation, Keio University, (2010).

25) H. Nanbu, S. Kikuchi, Y. Kameyama and J. Komotori, "Wear resistance of AISI316L steel modified by pre-FPP treated DLC coating", Journal of Solid Mechanics and Materials Engineering, Vol.3, No.2 pp.328-335 (2009).

26) S. Kikuchi, S. Yoshida, Y. Nakamura, K. Nambu and T. Akahori, "Characterization of the hydroxyapatite layer formed by fine hydroxyapatite particle peening and its effect on the fatigue properties of commercially pure titanium under four-point bending", Surface and Coatings Technology, Vol. 288, pp.196-202 (2016).

27) S. Ota, H. Akebono, S. Kikuchi, K. Murai, J. Komotori, K. Fukazawa, Y. Misaka and K. Kawasaki, "Surface modification of carbon steel by atmospheric-controlled IH-FPP treatment using mixed chromium and high-speed steel particles", Materials Transactions, Vol.57, No.10, pp.1801-1806 (2016).

28) S. Kikuchi, Y. Nakamura, K. Nambu and T. Akahori, "Formation of hydroxyapatite layer on Ti-6Al-4V ELI alloy by fine particle peening", International Journal of Automation Technology, Vol.11, No.6, pp.915-924 (2017).

29) S. Kikuchi, S. Iwamae, H. Akebono, J. Komotori and K. Kadota, "Effect of atmospheric-controlled induction-heating fine particle peening on electrochemical characteristics of austenitic stainless steel", Surface and Coatings Technology, Vol.334, pp.189-195 (2018)

30) S. Kikuchi, S. Iwamae, H. Akebono, J. Komotori and Y.
Misaka, "Improvement of the electrochemical characteristics of medium carbon steel using atmospheric-controlled induction-heating fine particle peening", Surface and Coatings Technology, Vol.354, pp.76-82 (2018)

31) S. Kikuchi, Y. Nakamura, K. Nambu and T. Akahori, "Formation of a hydroxyapatite layer on $\mathrm{Ti}-29 \mathrm{Nb}-13 \mathrm{Ta}-4.6 \mathrm{Zr}$ and enhancement of four-point bending fatigue characteristics by fine particle peening", International Journal of Lightweight Materials and Manufacture, Vol.2, No.3, pp.227-234 (2019).

32) S. Kikuchi, T. Fukuoka, T. Sasaki, J. Komotori, K. Fukazawa, Y. Misaka and K. Kawasaki, "Increasing surface hardness of AISI 1045 steel by AIH-FPP / Plasma nitriding treatment", Materials Transactions, Vol.54, No.3, pp.344-349 (2013).

33) S. Kikuchi, Y. Kameyama, M. Mizutani and J. Komotori, "Effects of fine particle peening on oxidation behavior of nickel-titanium shape memory alloy", Materials Transactions, Vol.55, No.1, pp.176-181 (2014). 